OPEN ACCESS

Edited by:

Korakot Nganvongpanit, Chiang Mai University, Thailand

Reviewed by: Krekwit Shinlapawittayatorn, Chiang Mai University, Thailand Soontaree Petchdee,

Kasetsart University, Thailand

*Correspondence Sirilak Disatian Surachetpong sirilakd27@gmail.com

Specialty section:

This article was submitted to Comparative and Clinical Medicine, a section of the journal

Frontiers in Veterinary Science

Received: 30 September 2020 Accepted: 10 November 2020 Published: 03 December 2020

Citation:

Sakarin S, Surachetpong SD and Rungsipipat A (2020) The Expression of Proteins Related to Serotonin Pathway in Pulmonary Arteries of

Dogs Affected With Pulmonary Hypertension Secondary to Degenerative Mitral Valve Disease. Front. Vet. Sci. 7:612130

doi: 10.3389/fvets.2020.612130

\section{The Expression of Proteins Related to Serotonin Pathway in Pulmonary Arteries of Dogs Affected With Pulmonary Hypertension Secondary to Degenerative Mitral Valve Disease}

\author{
Siriwan Sakarin ${ }^{1}$, Sirilak Disatian Surachetpong ${ }^{1 *}$ and Anudep Rungsipipat ${ }^{2}$ \\ ${ }^{1}$ Department of Veterinary Medicine, Faculty of Veterinary Science, Chulalongkorn University, Bangkok, Thailand, \\ ${ }^{2}$ Companion Animal Cancer Research Unit, Department of Veterinary Pathology, Faculty of Veterinary Science, \\ Chulalongkorn University, Bangkok, Thailand
}

Background: Pulmonary hypertension $(\mathrm{PH})$ can cause medial thickening, a hallmark of pulmonary arterial remodeling. The serotonin (5HT) pathway has been suggested as a factor associated with $\mathrm{PH}$ by inducing pulmonary arterial smooth muscle cells (SMCs) proliferation, a major cause of medial thickening. This study aims to demonstrate the expression of molecules in the 5HT pathway in the pulmonary artery of dogs affected with $\mathrm{PH}$ secondary to degenerative mitral valve disease (DMVD) compared to DMVD and healthy control dogs.

Materials and Methods: The study included lung samples from the carcasses of 19 older small-breed dogs (Control $n=5$, DMVD $n=7$, DMVD+PH $n=7$ ). Lung tissue sections were performed Hematoxylin and Eosin staining for measuring the percentage of medial thickness and immunohistochemistry for evaluating the expression of proteins in the $5 \mathrm{HT}$ pathway including serotonin transporter (SERT), serotonin 2A receptor (5HT2A), tryptophan hydroxylase $1(\mathrm{TPH} 1)$, extracellular regulated kinase 1/2 (ERK1/2), and phosphorylated ERK1/2 (pERK1/2).

Results: Medial thickening of the pulmonary arteries was found in the DMVD and $\mathrm{DMVD}+\mathrm{PH}$ groups compared to the control. The medial thickening of the DMVD+PH group was increased significantly compared to that in the DMVD group. Intracytoplasmic expression of proteins related to the $5 \mathrm{HT}$ pathway was mainly presented in the medial layer of the pulmonary arteries. The control group showed a low expression of proteins related to the $5 \mathrm{HT}$ pathway. An intensive expression of SERT, $5 \mathrm{HT} 2 \mathrm{~A}, \mathrm{TPH} 1$, and ERK1/2 protein was seen in the DMVD and DMVD+PH groups. Interestingly, pERK1/2 was strongly represented only in the DMVD+PH group.

Conclusions: Overexpression of proteins related to the $5 \mathrm{HT}$ pathway including SERT, $5 \mathrm{HT} 2 \mathrm{~A}$, TPH1, ERK1/2, and pERK1/2 was associated with medial remodeling in dogs affected with secondary to DMVD.

Keywords: degenerative mitral valve disease, hyperplasia, pulmonary artery, pulmonary hypertension, serotonin, smooth muscle cells 


\section{INTRODUCTION}

Pulmonary hypertension $(\mathrm{PH})$ has been defined as an abnormal increase in pulmonary arterial pressure (PAP). Several causes can mediate $\mathrm{PH}$ in dogs. Among these causes, left heart disease is suggested as being the most common cause of $\mathrm{PH}$ in dogs (1-4). Degenerative mitral valve disease (DMVD) is a common left heart disease in older small-sized breed dogs. It is a progressive disease of valve degeneration that impacts cardiovascular hemodynamics. Congestive heart failure and $\mathrm{PH}$ are common complications of late-stage $\operatorname{DMVD}(2,5,6)$.

The clinical presentation including syncope, respiratory distress and exercise intolerance are signs suggestive of PH. Right heart catheterization is a gold standard method for measuring PAP in humans, whereas echocardiography is an acceptable method for estimating PAP in veterinary medicine. According to the ACVIM consensus guideline for the diagnosis and treatment of PH in dogs, estimated PAP and anatomical cardiac changes assessed by echocardiography have been used to evaluate the probability of $\mathrm{PH}$ in dogs (4).

Pulmonary arterial remodeling, especially medial thickening is a hallmark of structural changes of the pulmonary artery presenting in all forms of $\mathrm{PH}$ in human patients (7-12), $\mathrm{PH}$-induced animal models (13-17) as well as dogs affected with PH secondary to DMVD (3). However, the etiology of this pathological change remains unclear.

Serotonin pathway has been suggested as being associated with $\mathrm{PH}$ by inducing pulmonary arterial smooth muscle cells (SMCs) proliferation, which is a major cause of medial thickening (18). Serotonin or 5-hydroxytryptamine (5HT) is synthesized from tryptophan through tryptophan hydroxylase 1 (TPH1), a rate-limiting enzyme in pulmonary arterial endothelial cells. Serotonin then stimulates pulmonary arterial SMCs proliferation in a paracrine fashion causing medial thickening. These effects of $5 \mathrm{HT}$ are mediated via the $5 \mathrm{HT}$ transporter (SERT) and $5 \mathrm{HT}$ receptors $(19,20)$. Although mechanisms of 5HT mediated pulmonary arterial SMCs proliferation remain unclear, several studies suggest 5HT transport into pulmonary arterial SMCs via SERT and 5HT receptors. Intracellular accumulation of 5HT induces reactive oxygen species and Rho-kinase activating phosphorylation and nuclear translocation of extracellular regulated kinase $1 / 2$ (ERK1/2), leading to an increase in transcription of nuclear growth factors and mediating cellular proliferation $(21,22)$. The serotonin pathway has been of interest as a factor associated with $\mathrm{PH}$ due to evidence showing that patients who use drugs which are SERT substrates develop $\mathrm{PH}$ $(19,20,23)$. In addition, a study in PH-induced animal models demonstrated that inhibition of SERT and 5HT receptors could reduce the risk of $\mathrm{PH}$ development (24).

Overexpression of proteins in the $5 \mathrm{HT}$ pathway has been suggested as being involved in $\mathrm{PH}$ by stimulating pulmonary

Abbreviations: DMVD, degenerative mitral valve disease; ECs, endothelial cells; ERK 1/2, extracellular regulated kinase 1/2; 5HT, 5-hydroxytryptamine, serotonin; 5HT2A, Serotonin 2A receptor; \%MT, percentage of medial thickness; PAP, pulmonary arterial pressure; pERK $1 / 2$, phosphorylated extracellular regulated kinase $1 / 2$; PH, pulmonary hypertension; SD, standard deviation; SERT, serotonin transporter; SMCs, smooth muscle cells; TPH1, tryptophan hydroxylase 1. artery SMCs proliferation (22). Previous studies reported an overexpression of SERT in human patients affected with primary PH $(18,25)$. A study in PH-induced animal models showed that not only SERT but also 5HT receptor overexpression was associated with pulmonary arterial SMCs hyperplasia (26). Although there is evidence supporting that the 5HT pathway is associated with the development of $\mathrm{PH}$ in both human patients and animal models, its effects on the pathogenesis of $\mathrm{PH}$ in DMVD dogs were not evaluated. This study aimed to demonstrate the expression of proteins related to the 5HT pathway in the pulmonary artery of dogs affected with $\mathrm{PH}$ secondary to DMVD compared to DMVD and healthy control dogs.

\section{MATERIALS AND METHODS}

\section{Animals}

Carcasses of 19 elder small-breed dogs presented at the Department of Pathology, Faculty of Veterinary Science, Chulalongkorn University for necropsy were selected into the study. The Ethical approval is not required because the study was performed in donation cadavers. Dogs were divided into three groups, including control $(n=5)$, degenerative mitral valve disease (DMVD) $(n=7)$ and degenerative mitral valve disease with pulmonary hypertension (DMVD+PH) groups ( $n$ $=7$ ), based on mitral valve thickness measured at necropsy and previous clinical diagnostic records. Dogs were excluded, if they had pulmonary diseases, heartworm infection, systemic hypertension, neoplasia, and other systemic diseases such as hepatic and kidney diseases evaluated by antemortem diagnostic history and gross pathology. Dogs with mitral valve thickness $<2 \mathrm{~mm}$ measured by Vernier caliper were included in the control group $(27,28)$. Dogs affected with DMVD had to have mitral valve thickness $>2 \mathrm{~mm}$ and had been diagnosed with DMVD stage C before death. All DMVD dogs had to have vertebral heart score more than 10.5 with either current or past signs of pulmonary edema assessed by radiography, left atrial and ventricular enlargement $[\mathrm{LA} / \mathrm{Ao} \geq 1.6$ (Swedish method) and left ventricular internal diameter during diastole normalized with the Allometric scale method (LVIDdN) $\geq 1.7]$ (6). Dogs in the DMVD+PH group had to have an intermediate to high probability of $\mathrm{PH}$ secondary to DMVD evaluated by estimated PAP and anatomic structural changes assessed by echocardiography (Figure 1) (4, 29).

Lung tissues were collected at peripheral regions of right caudal lung lobes and preserved in 10\% neutral buffered formalin for $24 \mathrm{~h}$ and embedded in paraffin blocks. Lung tissue sections ( $4 \mu \mathrm{m}$ thickness) were immunohistologically stained for proteins related to 5HT pathway including SERT, 5HT2A, ERK1/2, pERK1/2, and TPH1 following the modified protocols described by previous studies $(15,16,18,25,28,30-32)$. Briefly, tissue sections were deparaffinized, pre-treated with citrate buffer, $\mathrm{pH}$ 6.0, blocked endogenous peroxidase activity and non-specific antibody binding. The sections were incubated with primary antibodies including monoclonal mouse antiSERT antibody (Advanced Targeting Systems, Cat\# AB-N40, RRID:AB_2868504), monoclonal mouse anti-5HT2A (Santa 


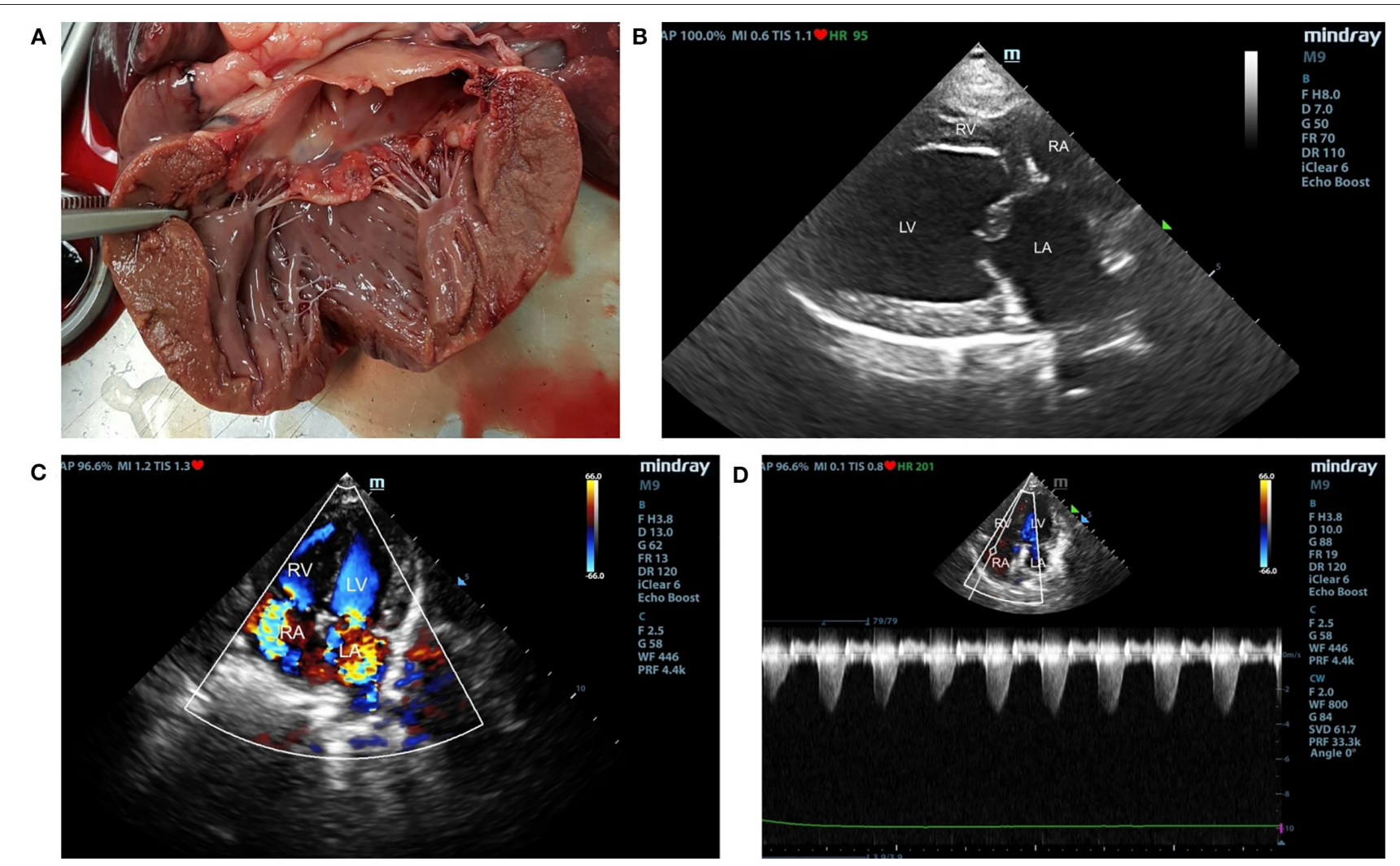

FIGURE 1 | The gross pathology of mitral valve leaflet (A) and echocardiographic findings of degenerative mitral valve disease (DMVD) dogs with pulmonary hypertension (PH) (B-D). The affected mitral valve leaflets are nodular and thickening (A). Echocardiography from two-dimensional right parasternal four chamber view showed thickening of mitral valve leaflets and left atrial (LA) enlargement (B). Color-flow Doppler echocardiography shows mitral valve and tricuspid valve regurgitation jets (C). Spectral Doppler echocardiography of tricuspid regurgitation in DMVD dogs with PH. Peak systolic tricuspid regurgitation velocity were measured to evaluate estimated pulmonary arterial pressure (PAP) (D).

Cruz Biotechnology, Cat\# sc-166775, RRID:AB_2233203), monoclonal rabbit anti-ERK1/2 and pERK1/2 (Cell Signaling Technology, Cat\# 8201, RRID:AB_10695902), and monoclonal mouse anti-TPH1 (Sigma-Aldrich, Cat\# T0678, RRID:AB_261587) at dilution 1:200 overnight. Tissue sections were then incubated with horse radish peroxidase-labeled polymer conjugated with secondary antibody (Dako, Cat\# K5007). Sections were incubated with 3,3'-diaminobenzidine tetrahydrochloride (Dako, Cat\# K5007) diluted 1:50 for visualizing peroxidase activity and counterstained with Mayer's hematoxylin.

Ten pulmonary arteries with the external diameter approximately $300 \mu \mathrm{m}$ from each dog were microscopically examined under a light microscope and randomly photographed with a photomicroscope (Olympus BX50 ${ }^{\circledR}$, Olympus Optical, Tokyo, Japan) at 100x magnification for measuring internal and external diameters and calculating the percentage of medial thickness (\%MT) as following equation: (external diameter internal diameter)/external diameter $\times 100$. Five areas of each pulmonary artery were photographed at 400x magnification for measuring the positive areas using an image analyzer program (Image-Pro ${ }^{\circledR}$ Plus Software, RRID:SCR_007369, version \#6.0).
The percentage of the positive area was calculated by dividing the positive area by the total area. The average positive areas of each antibody were calculated.

\section{Statistical Analysis}

Statistical analysis was performed by the computer-based software (SPSS, RRID:SCR_002865). The Shapiro-Wilk test was used for the normality test. Normally distributed data were presented as mean \pm standard deviation (SD). One-way ANOVA was used for evaluating differences among the control, DMVD and DMVD+PH groups. LSD test was used for post-hoc analysis and the $p$-value for pairwise comparison was adjusted by Bonferroni correction $p$-value of $<0.05$ was considered statistically significant.

\section{RESULTS}

\section{Clinical Characteristics of Dogs}

The characteristics of dogs recruited to the study are summarized in Table 1. Age, weight, and sex of dogs in the control, DMVD and DMVD+PH groups were not different. The thickness of mitral valve in the DMVD and DMVD+PH groups was 
TABLE 1 | The clinical characteristic of dog in the control, degenerative mitral valve disease (DMVD), and degenerative mitral valve disease with pulmonary hypertension (DMVD+PH) groups.

\begin{tabular}{|c|c|c|c|c|}
\hline Parameters & Control $(n=5)$ & DMVD $(n=7)$ & DMVD+PH $(n=7)$ & $p$-value \\
\hline Age (year) & $11.20 \pm 3.63$ & $13.71 \pm 1.80$ & $13.86 \pm 1.57$ & 0.136 \\
\hline Weight (kg) & $5.59 \pm 0.38$ & $4.91 \pm 1.49$ & $6.25 \pm 2.99$ & 0.486 \\
\hline \multicolumn{5}{|l|}{ Sex } \\
\hline Male & $3(\mathrm{M}=1 ; \mathrm{Mc}=2)$ & $3(\mathrm{M}=1 ; \mathrm{Mc}=2)$ & $4(\mathrm{M}=2 ; \mathrm{Mc}=2)$ & \\
\hline Female & $2(F=1 ; F s=1)$ & $4(F=2 ; F s=2)$ & $3(F=2 ; F s=1)$ & \\
\hline Breed & $\begin{array}{l}\text { Shih Tzu }(n=3) \text {, Mixed }(n=1) \\
\text { Pomeranian }(n=1)\end{array}$ & $\begin{array}{l}\text { Poodle }(n=4) \text {, Shih Tzu }(n=2) \text {, } \\
\text { Pomeranian }(n=1)\end{array}$ & $\begin{array}{c}\text { Poodle }(n=2) \text {, Chihuahua }(n=2) \text {, Pomeranian } \\
(n=1), \text { Schnauzer }(n=1), \text { Shih Tzu }(n=1)\end{array}$ & \\
\hline Mitral valve thickness (mm) & $0.60 \pm 0.21$ & $2.40 \pm 0.16^{a}$ & $2.54 \pm 0.15^{a}$ & ${ }^{a}<0.0001$ \\
\hline LA/Ao & - & $2.05 \pm 0.36$ & $2.24 \pm 0.79$ & 0.595 \\
\hline LVIDdN & - & $2.08 \pm 0.41$ & $1.71 \pm 0.39$ & 0.142 \\
\hline
\end{tabular}

Data are expressed as mean \pm standard deviation (SD).

The significant difference was assessed by the one-way ANOVA at $p<0.05$.

aIndicate significant difference at $p<0.05$ compared to the control group.

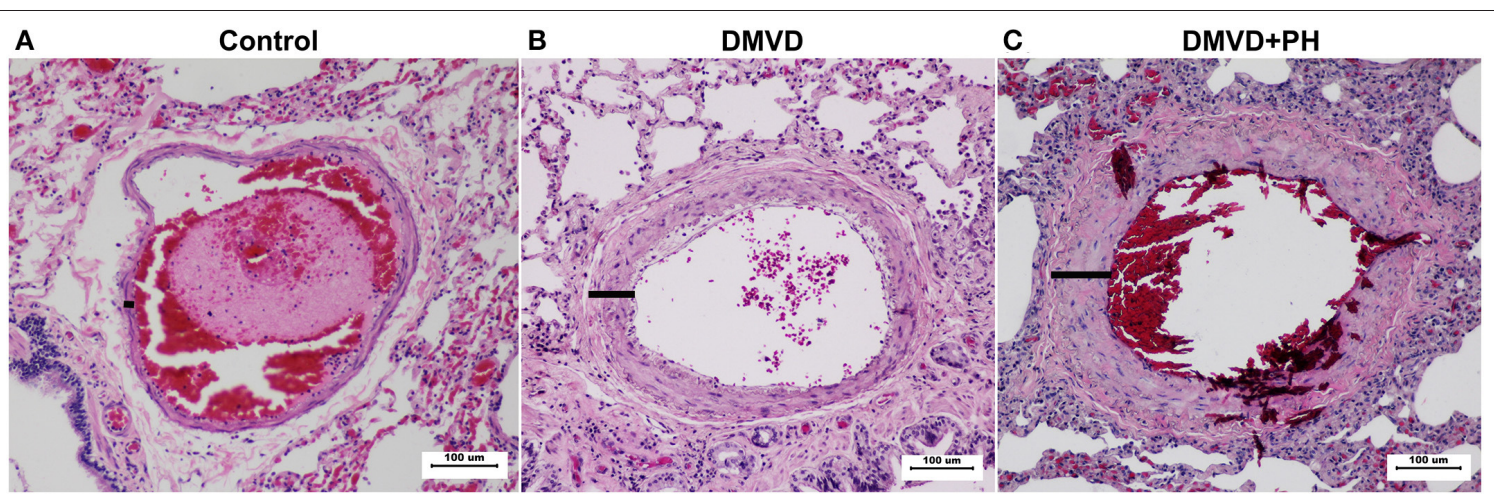

FIGURE 2 | The histopathology of the pulmonary artery in the control (A), degenerative mitral valve disease (DMVD) (B) and degenerative mitral valve disease with pulmonary hypertension (DMVD+PH) (C) groups (Hematoxylin and eosin stain, 100x magnification). Medial thickness of the pulmonary arteries were increased in the DMVD and DMVD+PH groups compared to the control group.

significantly thicker than the control group (Table 1). The cause of death of DMVD dogs with and without PH was cardiovascular failure. Only one dog in the DMVD+PH group was euthanized due to non-response to cardiovascular drugs. Dogs in the control group died secondary to postoperative complications and the car accident. None of dogs in the control group had abnormality of heart and lungs. Based on antemortem echocardiographic findings, LA/Ao and LVIDdN was not different between the DMVD and DMVD+PH groups (Table 1). The average estimated PAP of dogs in the DMVD $+\mathrm{PH}$ groups was $75.77 \pm$ $28.79 \mathrm{mmHg}$ (range $49.51-116 \mathrm{mmHg}$ ). Five of seven dogs in the $\mathrm{DMVD}+\mathrm{PH}$ group had anatomic changes including right side of the heart and pulmonary artery enlargement.

\section{Percentage of Medial Thickness}

Pulmonary arteries in dogs with DMVD and DMVD with $\mathrm{PH}$ were presented with medial thickening (Figure 2). The percentage of medial thickness (\%MT) was increased in the DMVD $(22.36 \pm 1.44 \%)$ and DMVD $+\mathrm{PH}$ groups $(32.25 \pm$ $5.06 \%)$ compared to the control group $(11.04 \pm 0.95 \%)(p<$
0.0001). In addition, \%MT was increased in the DMVD+PH group compared to that in the DMVD group $(p<0.0001)$. An increase in smooth muscle layers was seen in the DMVD and DMVD+PH groups.

\section{Immunolocalization of Proteins Related to in 5HT Pathway}

The expression of SERT, 5HT2A, TPH1, ERK1/2, and pERK1/2 were found mainly in the medial layer of the pulmonary artery. The expression of SERT, 5HT2A, and TPH1 was observed in the cytoplasm of pulmonary arterial SMCs (Figure 3). ERK1/2 and pERK1/2, downstream signaling proteins of 5HT pathway were expressed in the nucleus and cytoplasm of pulmonary arterial SMCs but predominantly located in the cytoplasm (Figure 4). In the control group, the percentage of SERT, 5HT2A, TPH1, and ERK1/2 positive area was very low, and they were significantly increased in the DMVD and DMVD+PH groups (Table 2, Figure 5). Although ERK1/2 was presented in all groups, pERK1/2 was presented only in the DMVD+PH group (Figure 4). In the DMVD+PH group, the expression of SERT, 


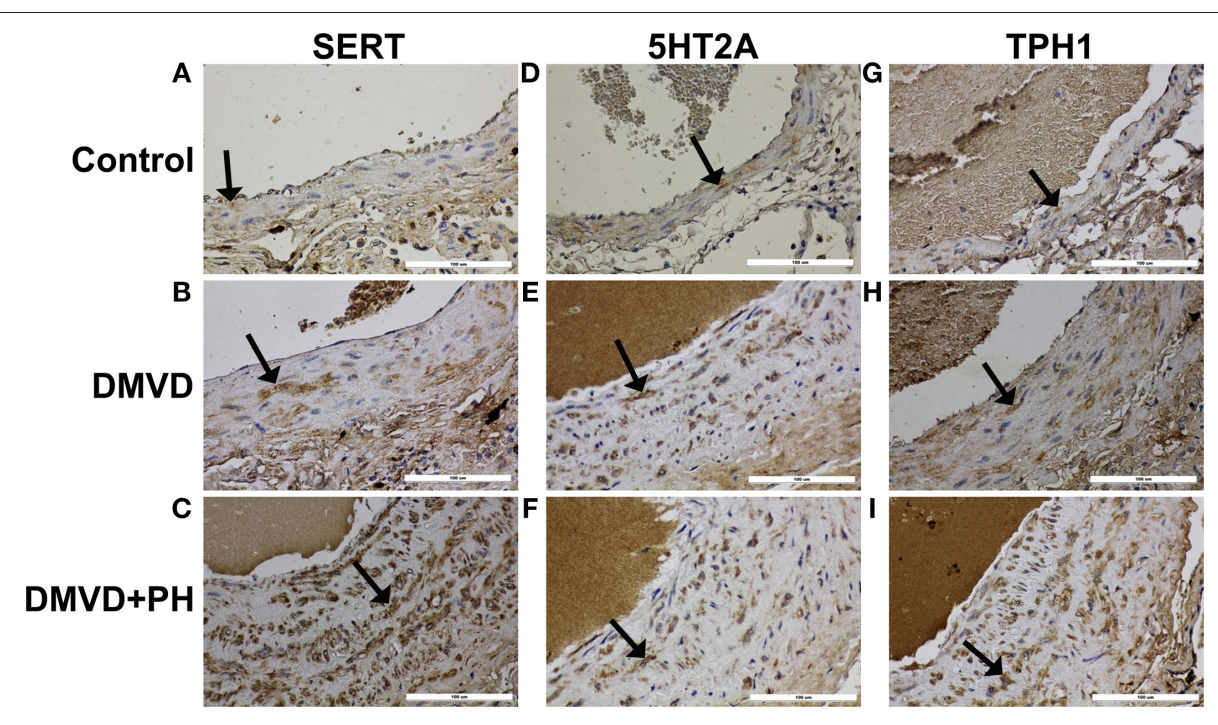

FIGURE 3 | The expression of protein related to $5 \mathrm{HT}$ pathway including serotonin transporter (SERT), serotonin 2A receptor (5HT2A), tryptophan hydroxylase 1 $(\mathrm{TPH} 1)$ in pulmonary arterial smooth muscle cells of the control (A,D,G), degenerative mitral valve disease (DMVD) (B,E,H) and degenerative mitral valve disease with pulmonary hypertension (DMVD+PH) groups (C,F,I). The SERT, 5HT2A and TPH1 expression in cytoplasm of pulmonary arterial smooth muscle cells presented as brown color (Labeled streptavidin-biotin, Immunohistochemistry, Mayer's Hematoxylin counterstained, 400x magnification).

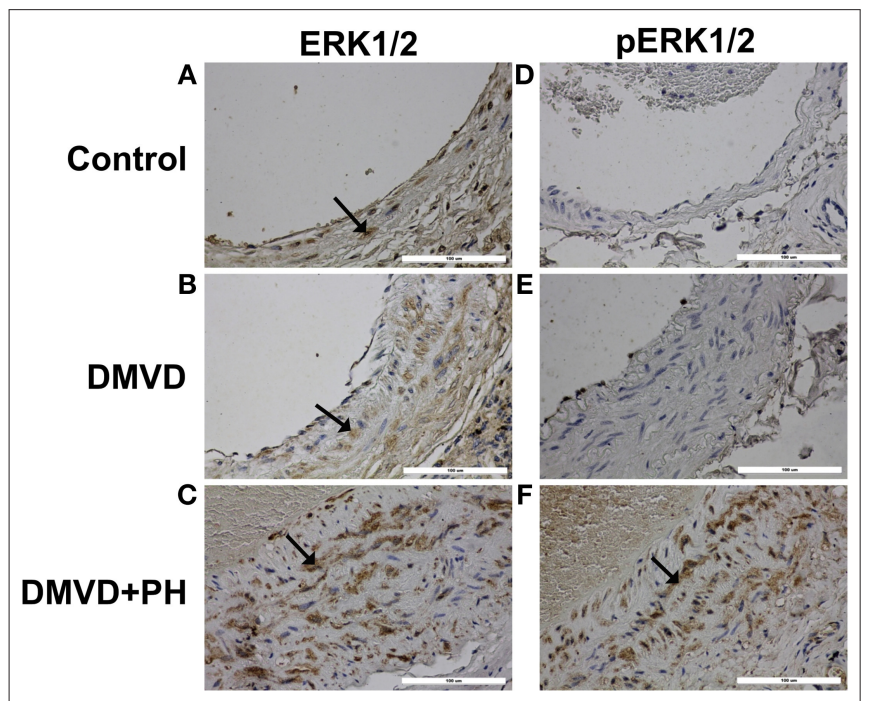

FIGURE 4 | The expression of downstream molecules in 5HT pathway including extracellular regulated kinase 1/2 (ERK1/2) and phosphorylated ERK1/2 (pERK1/2) in pulmonary arterial smooth muscle cells of the control $(\mathbf{A}, \mathbf{D})$, degenerative mitral valve disease (DMVD) $\mathbf{( B , E )}$ and degenerative mitral

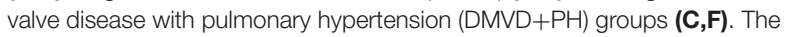
ERK $1 / 2$ and $p E R K 1 / 2$ expressed in both nucleus and cytoplasm of pulmonary arterial smooth muscle cells but predominantly located in cytoplasm presenting as brown color (Labeled streptavidin-biotin, Immunohistochemistry, Mayer's Hematoxylin counterstained, 400x magnification).

TPH1, ERK, pERK was significantly increased compared to the DMVD group. Only the expression of 5HT2A that was not significantly different between the DMVD and DMVD+PH groups (Table 2, Figures 3, 5).
The \%MT was strongly correlated with the expression of proteins related to 5HT pathway including SERT $(r=0.923$, $p<0.0001)$, 5HT2A $(r=0.821, p<0.0001)$, TPH1 $(r=$ 0.932, $p<0.0001)$, ERK1/2 $(r=0.854, p<0.0001)$, pERK1/2 $(r=0.754, p<0.0001)$.

\section{DISCUSSION}

Pulmonary arterial remodeling has been reported in human patients affected with $\mathrm{PH}$ and $\mathrm{PH}$-induced animal models (7$14,16,17,33-36)$. Histopathological changes of the pulmonary artery affect all elements of the pulmonary arterial walls including the tunica intima, tunica media, and tunica adventitia. While intimal and adventitial remodeling was not found in all forms of $\mathrm{PH}$, medial remodeling was a common pathological change found in humans affected with $\mathrm{PH}(8,9,11,12,37,38)$ and $\mathrm{PH}-$ induced animal models (13-17). This study reveals that all dogs in the DMVD and DMVD+PH groups had increased medial thickness similar to previous studies in dogs $(1,3)$ and human patients affected with $\mathrm{PH}$ secondary to left-sided heart failure (39). Interestingly, DMVD dogs with PH had \%MT greater than those without $\mathrm{PH}$, suggesting further progression of medial remodeling in DMVD dogs with $\mathrm{PH}$.

The serotonin pathway has been proven to relate to pulmonary vascular remodeling in humans with $\mathrm{PH}$ and $\mathrm{PH}-$ induced animal models. Serotonin signaling has been suggested as being involved with the pathogenesis of DMVD in dogs (40$44)$ and humans $(45,46)$ but very little is known about its effects on the pathogenesis of $\mathrm{PH}$ in dogs with DMVD. Serotonin can be used to induce $\mathrm{PH}$ in a canine animal model, suggesting involvement of 5HT in the pathogenesis of PH in dogs (47-52). However, there is no study of naturally occurring $\mathrm{PH}$ in dogs with 
TABLE 2 | The percentage of SERT, 5HT2A, TPH1, ERK1/2, pERK1/2 positive areas in the control, degenerative mitral valve disease (DMVD) and degenerative mitral valve disease with pulmonary hypertension (DMVD+PH) groups.

\begin{tabular}{lcccc}
\hline $\begin{array}{l}\text { Parameters } \\
(\%)\end{array}$ & $\begin{array}{c}\text { Control } \\
(\boldsymbol{n}=\mathbf{5})\end{array}$ & DMVD $(\boldsymbol{n}=\mathbf{7})$ & $\begin{array}{c}\text { DMVD+PH } \\
(\boldsymbol{n}=\mathbf{7})\end{array}$ & $\boldsymbol{p}$-value \\
\hline SERT & $0.58 \pm 0.05$ & $4.56 \pm 0.44^{\mathrm{a}, \mathrm{b}}$ & $9.87 \pm 0.43^{\mathrm{a}, \mathrm{c}}$ & $<0.0001$ \\
$5 \mathrm{HT} 2 \mathrm{~A}$ & $1.48 \pm 0.11$ & $6.45 \pm 0.46^{\mathrm{a}}$ & $7.06 \pm 0.83^{\mathrm{a}}$ & $<0.0001$ \\
TPH1 & $0.86 \pm 0.19$ & $5.43 \pm 0.34^{\mathrm{a}, \mathrm{b}}$ & $8.07 \pm 0.73^{\mathrm{a}, \mathrm{c}}$ & $<0.0001$ \\
ERK & $0.80 \pm 0.21$ & $1.61 \pm 0.47^{\mathrm{a}, \mathrm{b}}$ & $7.78 \pm 0.35^{\mathrm{a}, \mathrm{c}}$ & $<0.0001$ \\
pERK & $0.00 \pm 0.00$ & $0.00 \pm 0.00^{\mathrm{b}}$ & $6.61 \pm 0.85^{\mathrm{a}, \mathrm{c}}$ & $<0.0001$ \\
\hline
\end{tabular}

Data are expressed as mean \pm standard deviation (SD).

The significant difference was assessed by one-way ANOVA at $p<0.05$.

a Indicate significant difference at $p<0.05$ compared to the control group.

${ }^{b, c}$ Indicate significant difference at $p<0.05$ between the DMVD and DMVD+PH groups.

DMVD. To the authors' knowledge, this is the first study that examining the expression of proteins related to the $5 \mathrm{HT}$ pathway in the pulmonary arteries of dogs affected with $\mathrm{PH}$ secondary to DMVD.

The results showed a strong expression of proteins related to the 5HT pathway in DMVD dogs both with and without $\mathrm{PH}$ compared to control dogs. The expression of SERT was predominantly located in the medial layer of the pulmonary artery. The percentage of the SERT positive area was significantly higher in the DMVD and DMVD+PH groups compared to the control group. In addition, the expression of SERT was increased in the DMVD+PH group compared with the DMVD group. Similar findings have been reported in various forms of $\mathrm{PH}$ in human patients including idiopathic $\mathrm{PH}$ (53), primary $\mathrm{PH}$ $(18,25)$ and secondary $\mathrm{PH}$ from various diseases $(18)$ and in $\mathrm{PH}-$ induced animal models $(16,26,54,55)$. The results of the present study showed a relationship between an overexpression of SERT and the medial remodeling of the pulmonary artery in dogs affected with $\mathrm{PH}$ secondary to DMVD. Interestingly, DMVD dogs without $\mathrm{PH}$ also presented with SERT overexpression. Eddahibi et al. (38) reported that hypoxia could increase the rate of transcription of the SERT gene in pulmonary arterial SMCs. Moreover, experimental studies in mice showed that SERT was overexpressed during hypoxia $(26,56)$. Taken together, it is possible that hypoxia from pulmonary edema in DMVD dogs might be one of the factors that induces an increase in SERT expression in pulmonary arterial SMCs and stimulates medial remodeling.

Several studies have provided evidence that not only SERT but also 5HT receptors contribute to medial remodeling $(18,57-$ 63). 5 HT receptors can be divided into seven families (5HT1-7) (22). The 5HT2A receptor was selected for this study because it has been reported to mediate the effects of $5 \mathrm{HT}$ induced pulmonary arterial remodeling in animal models $(61,64)$. In addition, the 5HT2A receptor has been found in coronaries of dogs, and contributes to vasoconstriction induced by $5 \mathrm{HT}$ (65). The present study showed that 5HT2A was expressed in the medial layer of the pulmonary artery in the control, DMVD and DMVD+PH groups. The expression of 5HT2A was increased in the DMVD and DMVD+PH groups compared to the control

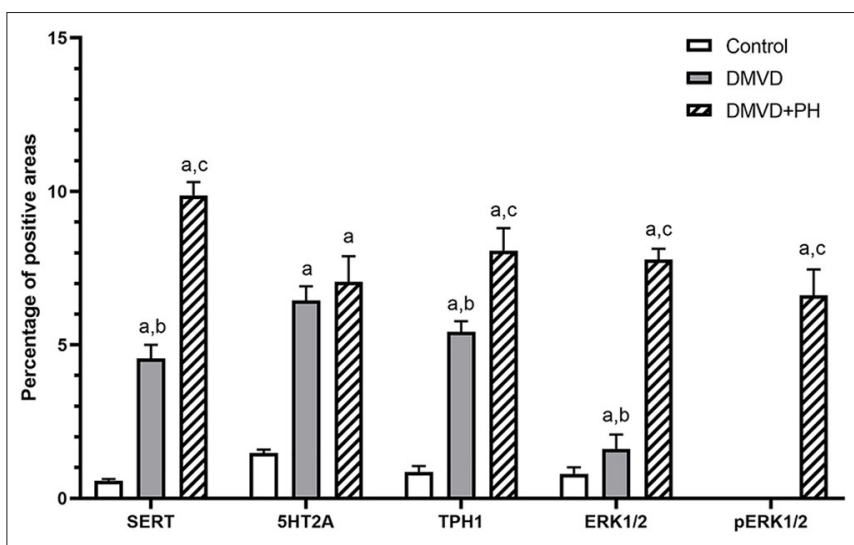

FIGURE 5 | The average percentage of positive areas of molecules in 5HT pathway in the control, degenerative mitral valve disease (DMVD) and degenerative mitral valve disease with pulmonary hypertension (DMVD+PH) groups. Data are expressed as mean and standard deviation (bars). ${ }^{a}$ Indicate significant difference at $p<0.05$ compared to the control group. ${ }^{\mathrm{b}, \mathrm{c}}$ Indicate significant difference at $p<0.05$ between the DMVD and DMVD+PH groups.

group. In contrast to studies in human patients with $\mathrm{PH}$ and $\mathrm{PH}-$ induced mice, the expression of $5 \mathrm{HT}$ receptors including $5 \mathrm{HT} 2 \mathrm{~A}$ was no different between the $\mathrm{PH}$ and control groups $(18,59)$. Interestingly, the percentage of the 5HT2A positive area was no different between the DMVD and DMVD+PH groups. It might be speculated that an upregulation of 5HT2A might be constant in DMVD dogs with and without $\mathrm{PH}$.

Not only $5 \mathrm{HT} 2 \mathrm{~A}$ receptor but also $5 \mathrm{HT} 1 \mathrm{~B}$ receptor has been reported to be involved with pulmonary hypertension in humans and large animal models such as pigs $(20,57,58,60,62)$. A previous study showed that the $5 \mathrm{HT} 1 \mathrm{~B}$ receptor has a role in constriction of the coronary artery in a dog model (65). However, the relationship of $5 \mathrm{HT} 1 \mathrm{~B}$ receptor and pulmonary hypertension in dogs has not been studied yet. Further studies are needed to be performed to evaluate the expression and roles of 5HT1B in pulmonary artery of DMVD dogs with $\mathrm{PH}$.

The results of this study suggest that SERT and 5HT2A may work incorporation in pulmonary arterial remodeling in DMVD dogs. Previous studies showed that SERT inhibitors reduced the proliferation of pulmonary arterial SMCs $(18,66)$, and they can protect the development of $\mathrm{PH}$ secondary to hypoxia (67) and monocrotaline induction (55). The 5HT2A antagonist reduced pulmonary arterial SMCs proliferation in both normoxic and hypoxic conditions (32). Moreover, the combination of the 5HT receptor antagonist and SERT antagonist can reduce pulmonary arterial SMCs proliferation in response to 5HT (62) and is more effective than using SERT inhibitors alone (68).

$\mathrm{TPH} 1$, a rate-limiting enzyme for 5HT synthesis has been suggested as being associated with PH (16). In humans, TPH1 catalyzed tryptophan to 5HT in pulmonary arterial endothelial cells (ECs) and then stimulates pulmonary arterial SMCs proliferation in a paracrine fashion causing medial remodeling $(19,20)$. Interestingly, the results of the present study showed that TPH1 was mainly expressed in the pulmonary arterial SMCs rather than the ECs in all three groups. On the contrary, 
previous studies in $\mathrm{PH}$-induced animal models noted that TPH1 expression was present only in pulmonary arterial ECs but not in SMCs $(32,69)$. The percentage of the TPH1 positive area was very low in the control group and significantly increased in the DMVD and DMVD+PH groups. Additionally, the TPH1 positive area increased in the DMVD+PH group compared to the DMVD group. A previous study showed a weak expression of TPH1 in normoxic mice (22). Chronic hypoxia can induce an increase of TPH1 expression and synthesis (20). Taken together, it is reasonable to speculate that chronic hypoxia from pulmonary edema may be one of the factors that induce an increased expression of TPH1 in DMVD dogs.

Although the mechanisms by which SERT and 5HT receptors mediate pulmonary arterial SMCs proliferation remain unclear, several studies have suggested that 5HT transport into SMCs via SERT and 5HT receptors and intracellular accumulation of $5 \mathrm{HT}$ induce reactive oxygen species and Rho-kinase activating phosphorylation and nuclear translocation of ERK1/2, leading to an increase in transcription of nuclear growth factors and mediation of cellular proliferation $(21,22)$. Activation of ERK1/2 is an important mechanism in 5HT-induced pulmonary arterial SMCs proliferation and is associated with the pathophysiology of $\mathrm{PH}$. The present study examined the expression of ERK1/2 and pERK1/2, which are downstream molecules of the 5HT pathway in the pulmonary artery. The results showed that ERK1/2 and pERK1/2 were present in the nucleus and cytoplasm of pulmonary arterial SMCs but were predominantly located in the cytoplasm. The percentage of ERK1/2 positive areas was very low in the control group but was significantly increased in the DMVD and DMVD+PH groups. However, pERK1/2 was increased only in the DMVD $+\mathrm{PH}$ group. The in vivo study of pulmonary arterial SMCs in humans (32) and rats (70) showed that ERK1/2 and pERK1/2 expression was increased in hypoxic conditions determined by western blot. An increase in ERK1/2 expression in DMVD dogs may occur secondary to chronic hypoxia from pulmonary edema. Interestingly, although, SERT, 5HT2A, TPH1, and ERK1/2 were overexpressed in DMVD dogs with and without $\mathrm{PH}, \mathrm{pERK} 1 / 2$ was increased only in DMVD dogs with $\mathrm{PH}$. These results suggest that activation of the $5 \mathrm{HT}$ signaling pathway through ERK1/2 may occur mainly in DMVD dogs with $\mathrm{PH}$.

Several studies in culture cells demonstrated that TPH1 (53) and SERT inhibitors could reduce pulmonary arterial SMCs proliferation $(18,66)$. Moreover, an inhibition of TPH1 and SERT can reduce the development of $\mathrm{PH}$ secondary to hypoxia and monocrotaline induction in animal models $(55,67)$. The present study reported the association between $\mathrm{PH}$ in DMVD dogs and an upregulation of proteins related to $5 \mathrm{HT}$ pathway. The selective

\section{REFERENCES}

1. Kellihan HB, Stepien RL. Pulmonary hypertension in dogs: diagnosis and therapy. Vet Clin North Am Small Anim Pract. (2010) 40:623-41. doi: 10.1016/j.cvsm.2010.03.011

2. Borgarelli M, Buchanan JW. Historical review, epidemiology and natural history of degenerative mitral valve disease. J Vet Cardiol. (2012) 14:93-101. doi: 10.1016/j.jvc.2012.01.011 inhibitors of TPH1, SERT and 5HT2A receptor may be the target of interests for further investigation to reduce the development of $\mathrm{PH}$ secondary to DMVD.

In conclusion, medial remodeling of the pulmonary artery in DMVD dogs with $\mathrm{PH}$ is associated with an upregulation of proteins related to the $5 \mathrm{HT}$ signaling pathway. Further studies are necessary to investigate the mechanisms of the 5HT signaling pathway in mediating $\mathrm{PH}$ in dogs affected with DMVD. A better understanding of the pathogenesis of $\mathrm{PH}$ in DMVD dogs will provide important insight into its management such as development target therapy or selective inhibitors for treatment or prevent $\mathrm{PH}$ secondary to DMVD in the future.

A limitation of this study was that the immunohistochemical study used an antibody against other species including humans, rabbits and rats instead of dogs. As because there are no available commercial antibodies against dogs and based on the amino acid sequence provided by UniProt, canine SERT, 5HT2A, TPH1, ERK1/2, and pERK1/2 are highly homologous (>90\%) to other species. Moreover, these antibodies have been successfully used in DMVD dogs $(27,28,71)$. Therefore, this antibody is reasonable for use in this present study.

\section{DATA AVAILABILITY STATEMENT}

The original contributions presented in the study are included in the article/supplementary materials, further inquiries can be directed to the corresponding author.

\section{AUTHOR CONTRIBUTIONS}

All authors listed have made a substantial, direct and intellectual contribution to the work, and approved it for publication.

\section{FUNDING}

This study was supported by the 90th Anniversary of Chulalongkorn University Fund (Ratchadaphiseksomphot Endowment Fund), the 100th Anniversary Chulalongkorn University Fund for Doctoral Scholarship, and The Thailand Research Fund, RSA6080009 to SS. The open access publication fees will be provided by Chulalongkorn University.

\section{ACKNOWLEDGMENTS}

The authors would like to thank all staffs at Department of Veterinary Pathology, Faculty of Veterinary Science, Chulalongkorn University for their helps in sample collection and laboratory facility support.
3. Kellihan HB, Stepien RL. Pulmonary hypertension in canine degenerative mitral valve disease. J Vet Cardiol. (2012) 14:149-64. doi: 10.1016/j.jvc.2012.01.001

4. Reinero C, Visser LC, Kellihan HB, Masseau I, Rozanski E, Clercx C, et al. ACVIM consensus statement guidelines for the diagnosis, classification, treatment, and monitoring of pulmonary hypertension in dogs. J Vet Intern Med. (2020) 34:549-73. doi: 10.1111/ jvim. 15725 
5. Chiavegato D, Borgarelli M, D'agnolo G, Santilli RA. Pulmonary hypertension in dogs with mitral regurgitation attributable to myxomatous valve disease. Vet Radiol Ultrasound. (2009) 50:253-8. doi: 10.1111/j.1740-8261.2009.01529.x

6. Keene BW, Atkins CE, Bonagura JD, Fox PR, Häggström J, Fuentes VL, et al. ACVIM consensus guidelines for the diagnosis and treatment of myxomatous mitral valve disease in dogs. J Vet Intern Med. (2019) 33:1127-40. doi: 10.1111 jvim. 15488

7. Moraes DL, Colucci WS, Givertz MM. Secondary pulmonary hypertension in chronic heart failure: the role of the endothelium in pathophysiology and management. Circulation. (2000) 102:1718-23. doi: 10.1161/01.CIR.102.14.1718

8. Delgado JF, Conde E, Sanchez V, Lopez-Rios F, Gomez-Sanchez MA, Escribano P, et al. Pulmonary vascular remodeling in pulmonary hypertension due to chronic heart failure. Eur J Heart Fail. (2005) 7:1011-6. doi: 10.1016/j.ejheart.2004.10.021

9. Savai R, Pullamsetti SS, Kolbe J, Bieniek E, Voswinckel R, Fink L, et al. Immune and inflammatory cell involvement in the pathology of idiopathic pulmonary arterial hypertension. Am J Respir Crit Care Med. (2012) 186:897908. doi: 10.1164/rccm.201202-0335OC

10. Gerges C, Gerges M, Lang MB, Zhang Y, Jakowitsch J, Probst P, et al. Diastolic pulmonary vascular pressure gradient: a predictor of prognosis in "out-of-proportion" pulmonary hypertension. Chest. (2013) 143:758-66. doi: $10.1378 /$ chest.12-1653

11. Guignabert C, Dorfmuller P. Pathology and pathobiology of pulmonary hypertension. Semin Respir Crit Care Med. (2013) 34:551-9. doi: 10.1055/s-0033-1356496

12. Muñoz-Esquerre M, López-Sánchez M, Escobar I, Huertas D, Penín R, Molina-Molina $\mathrm{M}$, et al. Systemic and pulmonary vascular remodelling in chronic obstructive pulmonary disease. PLoS ONE. (2016) 11:e0152987. doi: 10.1371/journal.pone.0152987

13. Zhai FG, Zhang XH, Wang HL. Fluoxetine protects against monocrotalineinduced pulmonary arterial hypertension: potential roles of induction of apoptosis and upregulation of Kv1.5 channels in rats. Clin Exp Pharmacol Physiol. (2009) 36:850-6. doi: 10.1111/j.1440-1681.2009.05168.x

14. Wang HM, Wang Y, Liu M, Bai Y, Zhang XH, Sun YX, et al. Fluoxetine inhibits monocrotaline-induced pulmonary arterial remodeling involved in inhibition of RhoA-Rho kinase and Akt signalling pathways in rats. Can J Physiol Pharmacol. (2012) 90:1506-15. doi: 10.1139/y2012-108

15. Liu M, Wang Y, Wang HM, Bai Y, Zhang XH, Sun YX, et al. Fluoxetine attenuates chronic methamphetamine-induced pulmonary arterial remodelling: possible involvement of serotonin transporter and serotonin 1B receptor. Basic Clin Pharmacol Toxicol. (2013) 112:77-82. doi: 10.1111/j.1742-7843.2012.00933.x

16. Bai Y, Wang H-M, Liu M, Wang Y, Lian G-C, Zhang X-H, et al. 4-Chloro-DLphenylalanine protects against monocrotaline induced pulmonary vascular remodeling and lung inflammation. Int J Mol Med. (2014) 33:373-82. doi: 10.3892/ijmm.2013.1591

17. Yang PS, Kim DH, Lee YJ, Lee SE, Kang WJ, Chang HJ, et al. Glycyrrhizin, inhibitor of high mobility group box-1, attenuates monocrotaline-induced pulmonary hypertension and vascular remodeling in rats. Respir Res. (2014) 15:148. doi: 10.1186/s12931-014-0148-4

18. Marcos E, Fadel E, Sanchez O, Humbert M, Dartevelle P, Simonneau $\mathrm{G}$, et al. Serotonin-induced smooth muscle hyperplasia in various forms of human pulmonary hypertension. Circ Res. (2004) 94:1263-70. doi: 10.1161/01.RES.0000126847.27660.69

19. Eddahibi S, Adnot S. The serotonin pathway in pulmonary hypertension. $A d v$ Pulm Hypertens. (2005) 4:20-3. doi: 10.21693/1933-088X-4.1.20

20. Dempsie Y, Maclean MR. Pulmonary hypertension: therapeutic targets within the serotonin system. Br J Pharmacol. (2008) 155:455-62. doi: 10.1038/bjp.2008.241

21. De Caestecker M. Serotonin signaling in pulmonary hypertension. Circ Res. (2006) 98:1229-31. doi: 10.1161/01.RES.0000225927.04710.33

22. Maclean MR, Dempsie Y. The serotonin hypothesis of pulmonary hypertension revisited. In: Yuan JX-J, Ward JPT, editors. Membrane Receptors, Channels and Transporters in Pulmonary Circulation. Totowa, NJ: Springer (2010). p. 309-22. doi: 10.1007/978-1-60761-500-2_20
23. Maclean MR, Dempsie Y. Serotonin and pulmonary hypertensionfrom bench to bedside? Curr Opin Pharmacol. (2009) 9:281-6. doi: 10.1016/j.coph.2009.02.005

24. Maclean MR. Pulmonary hypertension and the serotonin hypothesis: where are we now? Int J Clin Pract. (2007) 156:27-31. doi: 10.1111/j.1742-1241.2007.01497.x

25. Eddahibi S, Humbert M, Fadel E, Raffestin B, Darmon M, Capron F, et al. Serotonin transporter overexpression is responsible for pulmonary artery smooth muscle hyperplasia in primary pulmonary hypertension. J Clin Invest. (2001) 108:1141-50. doi: 10.1172/JCI200112805

26. Eddahibi S, Hanoun N, Lanfumey L, Lesch KP, Raffestin B, Hamon M, et al. Attenuated hypoxic pulmonary hypertension in mice lacking the 5-hydroxytryptamine transporter gene. J Clin Invest. (2000) 105:1555-62. doi: 10.1172/JCI8678

27. Disatian S, Ehrhart EJ, Zimmerman S, Orton EC. Interstitial cells from dogs with naturally occurring myxomatous mitral valve disease undergo phenotype transformation. J Heart Valve Dis. (2008) 17:402-11.

28. Disatian S, Lacerda C, Orton EC. Tryptophan hydroxylase 1 expression is increased in phenotype-altered canine and human degenerative myxomatous mitral valves. J Heart Valve Dis. (2010) 19:71.

29. Borgarelli M, Abbott J, Braz-Ruivo L, Chiavegato D, Crosara S, Lamb K, et al. Prevalence and prognostic importance of pulmonary hypertension in dogs with myxomatous mitral valve disease. J Vet Intern Med. (2015) 29:569-74. doi: $10.1111 /$ jvim. 12564

30. Milde-Langosch K, Bamberger AM, Rieck G, Grund D, Hemminger G, Müller V, et al. Expression and prognostic relevance of activated extracellularregulated kinases (ERK1/2) in breast cancer. Zentralbl Gynakol. (2005) 92:2206-15. doi: 10.1038/sj.bjc.6602655

31. Disatian S, Orton EC. Autocrine serotonin and transforming growth factor beta 1 signaling mediates spontaneous myxomatous mitral valve disease. $J$ Heart Valve Dis. (2009) 18:44-51.

32. Morecroft I, White K, Caruso P, Nilsen M, Loughlin L, Alba R, et al. Gene therapy by targeted adenovirus-mediated knockdown of pulmonary endothelial tph1 attenuates hypoxia-induced pulmonary hypertension. $\mathrm{Mol}$ Ther. (2012) 20:1516-28. doi: 10.1038/mt.2012.70

33. Said SI, Hamidi SA, Dickman KG, Szema AM, Lyubsky S, Lin RZ, et al. Moderate pulmonary arterial hypertension in male mice lacking the vasoactive intestinal peptide gene. Circulation. (2007) 115:1260-8. doi: 10.1161/CIRCULATIONAHA.106.681718

34. Guazzi M, Arena R. Pulmonary hypertension with left-sided heart disease. Nat Rev Cardiol. (2010) 7:648-59. doi: 10.1038/nrcardio.2010.144

35. Dumitrascu R, Kulcke C, Königshoff M, Kouri F, Yang X, Morrell N, et al. Terguride ameliorates monocrotaline-induced pulmonary hypertension in rats. Eur Respir J. (2011) 37:1104-18. doi: 10.1183/09031936.00126010

36. Liu Q, Song J, Lu D, Geng J, Jiang Z, Wang K, et al. Effects of renal denervation on monocrotaline induced pulmonary remodeling. Oncotarget. (2017) 8:46846-55. doi: 10.18632/oncotarget.15154

37. Chazova I, Robbins I, Loyd J, Newman J, Tapson V, Zhdaov V, et al. Venous and arterial changes in pulmonary veno-occlusive disease, mitral stenosis and fibrosing mediastinitis. Eur Respir J. (2000) 15:116-22. doi: 10.1183/09031936.00.15111600

38. Eddahibi S, Raffestin B, Hamon M, Adnot S. Is the serotonin transporter involved in the pathogenesis of pulmonary hypertension? J Lab Clin Med. (2002) 139:194-201. doi: 10.1067/mlc.2002.122181

39. Delgado JF. The pulmonary circulation in heart failure. Rev Esp Cardiol. (2010) 63:334-45. doi: 10.1016/S0300-8932(10)70092-0

40. Oyama MA, Levy RJ. Insights into serotonin signaling mechanisms associated with canine degenerative mitral valve disease. J Vet Intern Med. (2010) 24:27-36. doi: 10.1111/j.1939-1676.2009.0411.x

41. Ljungvall I, Hoglund K, Lilliehook I, Oyama MA, Tidholm A, Tvedten $\mathrm{H}$, et al. Serum serotonin concentration is associated with severity of myxomatous mitral valve disease in dogs. J Vet Intern Med. (2013) 27:1105-12. doi: $10.1111 /$ jvim. 12137

42. Cremer SE, Singletary GE, Olsen LH, Wallace K, Häggström J, Ljungvall I, et al. Serotonin concentrations in platelets, plasma, mitral valve leaflet, and left ventricular myocardial tissue in dogs with myxomatous mitral valve disease. $J$ Vet Intern Med. (2014) 28:1534-40. doi: 10.1111/jvim.12420 
43. Mangklabruks T, Surachetpong SD. Plasma and platelet serotonin concentrations in healthy dogs and dogs with myxomatous mitral valve disease. J Vet Cardiol. (2014) 16:155-62. doi: 10.1016/j.jvc.2014.05.003

44. Roels E, Krafft E, Antoine N, Farnir F, Laurila HP, Holopainen S, et al. Evaluation of chemokines CXCL8 and CCL2, serotonin, and vascular endothelial growth factor serum concentrations in healthy dogs from seven breeds with variable predisposition for canine idiopathic pulmonary fibrosis. Res Vet Sci. (2015) 101:57-62. doi: 10.1016/j.rvsc.2015.05.020

45. Hutcheson JD, Setola V, Roth BL, Merryman WD. Serotonin receptors and heart valve disease-it was meant 2B. Pharmacol Ther. (2011) 132:146-57. doi: 10.1016/j.pharmthera.2011.03.008

46. Goldberg E, Grau JB, Fortier JH, Salvati E, Levy RJ, Ferrari G. Serotonin and catecholamines in the development and progression of heart valve diseases. Cardiovasc Res. (2017) 113:849-57. doi: 10.1093/cvr/cvx092

47. Hashiba E, Hirota K, Yoshioka H, Hashimoto Y, Kudo T, Sato T, et al. Milrinone attenuates serotonin-induced pulmonary hypertension and bronchoconstriction in dogs. Anesth Analg. (2000) 90:790-4. doi: 10.1213/00000539-200004000-00004

48. Hashimoto Y, Hirota K, Yoshioka H, Hashiba E, Kudo T, Ishihara $\mathrm{H}$, et al. Spasmolytic effects of prostaglandin E1 on serotonin-induced bronchoconstriction and pulmonary hypertension in dogs. $\mathrm{Br} J$ Anaesth. (2000) 85:460-2. doi: 10.1093/bja/85.3.460

49. Hashimoto Y, Hirota K, Yoshioka H, Kudo T, Ishihara H, Matsuki A. A comparison of the spasmolytic effects of olprinone and aminophylline on serotonin-induced pulmonary hypertension and bronchoconstriction with or without beta-blockade in dogs. Anesth Analg. (2000) 91:1345-50. doi: 10.1097/00000539-200012000-00007

50. Yoshioka H, Hirota K, Sato T, Hashimoto Y, Ishihara H, Matsuki A. Spasmolytic effect of magnesium sulfate on serotonin-induced pulmonary hypertension and bronchoconstriction in dogs. Acta Anaesthesiol Scand. (2001) 45:435-40. doi: 10.1034/j.1399-6576.2001.045004435.x

51. Hirota K, Yoshioka H, Kabara S, Koizumi Y, Abe H, Sato T, et al. Spasmolytic effects of colforsin daropate on serotonin-induced pulmonary hypertension and bronchoconstriction in dogs. Acta Anaesthesiol Scand. (2002) 46:297-302. doi: 10.1034/j.1399-6576.2002.t01-1-460312.x

52. Lopes PCF, Nunes N, Paula DP, Nishimori CTD, Moro JV, Conceição EDV, et al. Cardiopulmonary parameters in propofol- or thiopental-anesthetized dogs induced to pulmonary hypertension by serotonin. Arq Bras Med Vet Zoo. (2015) 67:1231-40. doi: 10.1590/1678-4162-7421

53. Eddahibi S, Guignabert C, Barlier-Mur AM, Dewachter L, Fadel E, Dartevelle P, et al. Cross talk between endothelial and smooth muscle cells in pulmonary hypertension: critical role for serotonininduced smooth muscle hyperplasia. Circulation. (2006) 113:1857-64. doi: 10.1161/CIRCULATIONAHA.105.591321

54. Maclean MR, Deuchar GA, Hicks MN, Morecroft I, Shen S, Sheward J, et al. Overexpression of the 5-hydroxytryptamine transporter gene: effect on pulmonary hemodynamics and hypoxia-induced pulmonary hypertension. Circulation. (2004) 109:2150-5. doi: 10.1161/01.CIR.0000127375.56172.92

55. Guignabert C, Raffestin B, Benferhat R, Raoul W, Zadigue P, Rideau D, et al. Serotonin transporter inhibition prevents and reverses monocrotalineinduced pulmonary hypertension in rats. Circulation. (2005) 111:2812-9. doi: 10.1161/CIRCULATIONAHA.104.524926

56. Guignabert C, Izikki M, Tu LI, Li Z, Zadigue P, Barlier-Mur AM, et al. Transgenic mice overexpressing the 5-hydroxytryptamine transporter gene in smooth muscle develop pulmonary hypertension. Circ Res. (2006) 98:132330. doi: 10.1161/01.RES.0000222546.45372.a0

57. Keegan A, Morecroft I, Smillie D, Hicks MN, Maclean MR. Contribution of the 5-HT1B receptor to hypoxia-induced pulmonary hypertension. Circ Res. (2001) 89:1231-9. doi: 10.1161/hh2401.100426

58. Wang HL, Dong X, Zhang XH, Xing J. 5-HT1B receptor augmented 5HT vasoconstrictor response of pulmonary artery in monocrotaline-induced pulmonary hypertensive rats. Acta Pharmacol Sin. (2001) 22:269-73.
59. Launay JM, Herve P, Peoc'h K, Tournois C, Callebert J, Nebigil CG, et al. Function of the serotonin 5-hydroxytryptamine $2 \mathrm{~B}$ receptor in pulmonary hypertension. Nat Med. (2002) 8:1129-35. doi: 10.1038/nm764

60. Rondelet B, Van Beneden R, Kerbaul F, Motte S, Fesler P, Mcentee $\mathrm{K}$, et al. Expression of the serotonin $1 \mathrm{~b}$ receptor in experimental pulmonary hypertension. Eur Respir J. (2003) 22:408-12. doi: 10.1183/09031936.03.00036203

61. Welsh DJ, Harnett M, Maclean M, Peacock AJ. Proliferation and signaling in fibroblasts: role of 5-hydroxytryptamine2A receptor and transporter. Am J Respir Crit Care Med. (2004) 170:252-9. doi: 10.1164/rccm.200302-264OC

62. Lawrie A, Spiekerkoetter E, Martinez EC, Ambartsumian N, Sheward WJ, Maclean MR, et al. Interdependent serotonin transporter and receptor pathways regulate S100A4/Mts1, a gene associated with pulmonary vascular disease. Circ Res. (2005) 97:227-35. doi: 10.1161/01.RES.0000176025.57706.1e

63. Morecroft I, Loughlin L, Nilsen M, Colston J, Dempsie Y, Sheward J, et al. Functional interactions between 5-hydroxytryptamine receptors and the serotonin transporter in pulmonary arteries. J Pharmacol Exp Ther. (2005) 313:539-48. doi: 10.1124/jpet.104.081182

64. Cogolludo A, Moreno L, Lodi F, Frazziano G, Cobeño L, Tamargo $\mathrm{J}$, et al. Serotonin inhibits voltage-gated $\mathrm{K}+$ currents in pulmonary artery smooth muscle cells: role of 5-HT2A receptors, caveolin1, and KV1.5 channel internalization. Circ Res. (2006) 98:931-8. doi: 10.1161/01.RES.0000216858.04599.e1

65. Guilbert F, Lainée P, Dubreuil B, Mccort G, O'connor SE, Janiak P, et al. Serotonin aggravates exercise-induced cardiac ischemia in the dog: effect of serotonin receptor antagonists. Eur J Pharmacol. (2004) 497:55-63. doi: 10.1016/j.ejphar.2004.06.024

66. Dewachter L, Adnot S, Fadel E, Humbert M, Maitre B, Barlier-Mur AM, et al. Angiopoietin/Tie2 pathway influences smooth muscle hyperplasia in idiopathic pulmonary hypertension. Am J Respir Crit Care Med. (2006) 174:1025-33. doi: 10.1164/rccm.200602-304OC

67. Marcos E, Adnot S, Pham MH, Nosjean A, Raffestin B, Hamon $\mathrm{M}$, et al. Serotonin transporter inhibitors protect against hypoxic pulmonary hypertension. Am J Respir Crit Care Med. (2003) 168:487-93. doi: 10.1164/rccm.200210-1212OC

68. Morecroft I, Pang L, Baranowska M, Nilsen M, Loughlin L, Dempsie Y, et al. In vivo effects of a combined 5-HT1B receptor/SERT antagonist in experimental pulmonary hypertension. Cardiovasc Res. (2009) 85:593-603. doi: $10.1093 / \mathrm{cvr} / \mathrm{cvp} 306$

69. Gairhe S, Bauer NN, Gebb SA, Mcmurtry IF. Serotonin passes through myoendothelial gap junctions to promote pulmonary arterial smooth muscle cell differentiation. Am J Physiol Lung Cell Mol Physiol. (2012) 303:L767-777. doi: 10.1152/ajplung.00183.2012

70. Jiang R, Shi Y, Zeng C, Yu W, Zhang A, Du Y. Protein kinase C $\alpha$ stimulates hypoxia-induced pulmonary artery smooth muscle cell proliferation in rats through activating the extracellular signal-regulated kinase 1/2 pathway. $\mathrm{Mol}$ Med Rep. (2017) 16:6814-20. doi: 10.3892/mmr.2017.7478

71. Scruggs SM, Disatian S, Orton EC. Serotonin transmembrane transporter is down-regulated in late-stage canine degenerative mitral valve disease. $J$ Vet Cardiol. (2010) 12:163-9. doi: 10.1016/j.jvc.2010.06.002

Conflict of Interest: The authors declare that the research was conducted in the absence of any commercial or financial relationships that could be construed as a potential conflict of interest.

Copyright (c) 2020 Sakarin, Surachetpong and Rungsipipat. This is an open-access article distributed under the terms of the Creative Commons Attribution License (CC $B Y)$. The use, distribution or reproduction in other forums is permitted, provided the original author(s) and the copyright owner(s) are credited and that the original publication in this journal is cited, in accordance with accepted academic practice. No use, distribution or reproduction is permitted which does not comply with these terms. 